\title{
Article
}

\section{The Challenging Diagnosis of Pediatric Multisystem Inflammatory Syndrome Associated with Sars-Cov-2 Infection-Two Case Reports and Literature Review}

\author{
Marcela Daniela Ionescu ${ }^{1,2}$, Roxana Taras ${ }^{1,2}$, Bianca Dombici ${ }^{1}$, Mihaela Balgradean ${ }^{1,2}$, \\ Elena Camelia Berghea ${ }^{1,2, *}$ and Alin Nicolescu ${ }^{2}$ \\ 1 Department of Pediatrics, Carol Davila University of Medicine and Pharmacy, 020021 Bucharest, Romania; \\ daniela.ionescu@umfcd.ro (M.D.I.); roxana.taras@drd.umfcd.ro (R.T.); bianca.dombici@rez.umfcd.ro (B.D.); \\ mihaela.balgradean@umfcd.ro (M.B.) \\ 2 Marie Curie Emergency Children's Hospital, 041451 Bucharest, Romania; nicolescu_a@yahoo.com \\ * Correspondence: camelia.berghea@umfcd.ro
}

\section{check for} updates

Citation: Ionescu, M.D.; Taras, R.; Dombici, B.; Balgradean, M.; Berghea, E.C.; Nicolescu, A. The Challenging Diagnosis of Pediatric Multisystem Inflammatory Syndrome Associated with Sars-Cov-2 Infection-Two Case Reports and Literature Review. J. Pers Med. 2021, 11, 318. https://doi.org/ 10.3390/jpm11040318

Academic Editor: Pim A. de Jong

Received: 10 March 2021

Accepted: 14 April 2021

Published: 19 April 2021

Publisher's Note: MDPI stays neutral with regard to jurisdictional claims in published maps and institutional affiliations.

Copyright: (c) 2021 by the authors. Licensee MDPI, Basel, Switzerland. This article is an open access article distributed under the terms and conditions of the Creative Commons Attribution (CC BY) license (https:/ / creativecommons.org/licenses/by/ $4.0 /)$.

\begin{abstract}
Severe acute respiratory coronavirus 2 (SARS-CoV-2) is a novel coronavirus discovered in 2019 that caused the coronavirus disease 2019 (COVID19). During the last year, over 70 million people were infected and more than 1.5 million people died. Despite the tremendous number of people infected, children were less affected and presented milder forms of the disease. A short time after the pandemic was declared, a new hyperinflammatory syndrome resembling Kawasaki disease (KD) was described in children with confirmed or suspected SARS-CoV-2 infection named multisystem inflammatory syndrome in children (MIS-C). The incidence of MIS-C is low and it has a polymorphous clinical presentation, making the diagnosis difficult. Although the incidence is reduced, there is a high risk of cardiovascular complications. In order to raise awareness, we present the cases of two pediatric patients diagnosed with MIS-C in our clinic.
\end{abstract}

Keywords: multisystem inflammatory syndrome in children; cytokines; Kawasaki disease; pediatric COVID19-Kawasaki

\section{Introduction}

During the last year, the entire world confronted the pandemic caused by the SARSCoV-2 infection, first reported in Wuhan, China, which rapidly spread worldwide and caused catastrophic damages [1,2]. Although until this moment, over 70 million people have been infected, and more than 1.5 million people have died, children have been less affected [3]. In children, the SARS-CoV-2 infection produces mild, primarily respiratory or gastrointestinal symptoms in contrast to the severe forms in adult patients $[4,5]$. Despite the mild forms of the disease reported within pediatric population, a rare hyperinflammatory syndrome associated with coronavirus infection was described, initially named pediatric multisystem inflammatory syndrome temporally associated with SARS-CoV-2 infection (PIMS-TS) in Europe and multisystem inflammatory syndrome in children (MIS-C) in the United States $[4,6,7]$. The MIS-C clinical and paraclinical presentation has common characteristics with the presentation of KD, including fever, high levels of inflammatory markers, and multisystem damage (e.g., hematologic, dermatologic, cardiac) [8,9]. Large case series of KD related to SARS-CoV-2 infection from the United Kingdom (UK), Italy, the United States (USA), and France were published last year [1,4,9-12]. The MIS-C diagnosis can be difficult due to its polymorphous presentation and the shortage of knowledge of a previously SARS-CoV-2 infection which may be asymptomatic in pediatric patients $[13,14]$. Compared to KD, MIS-C has a higher risk of cardiovascular derangement and a higher rate of mortality therefore, it needs prompt diagnosis and treatment [4]. Of cardiovascular complications, specific data about arrhythmias are yet to be published [15]. From the information published so far, it is worth remembering that atrial flutter is very rarely 
described, both in adult and pediatric patients with COVID19, and the onset of this type of arrhythmia represents a negative biomarker predicting mortality [16,17].

To increase the degree of recognition of the potential for severe evolution and diagnostic framing difficulties, we selected 2 MIS-C cases from the Department of Pediatrics of Marie Curie Children's Emergency Hospital, Bucharest, Romania.

\subsection{Case Presentation \#1}

We present the case of a 4 year and 9-month-old male patient, who was admitted to the pediatric department of "Marie Curie" Emergency Children's Hospital, for fever $\left(39.2^{\circ} \mathrm{C}\right)$ which started 2 days before hospitalization, associated with generalized macular erythematous skin rash.

The history of present illness does not include any upper or lower respiratory tract infection or any gastrointestinal infection in the last 3 months nor a close contact with confirmed or suspected COVID 19 individuals in the last 4 weeks.

In the emergency department, the vital signs included a temperature of 38 degrees, respiratory rate of 20 breaths $/ \mathrm{min}$, oxygen saturation of $99 \%$ on room air, heart rate of 135 beats $/ \mathrm{min}$, and blood pressure of $95 / 51 \mathrm{mmHg}$. In the emergency department, the vital signs included a temperature of $38^{\circ} \mathrm{C}$, respiratory rate of $20 \mathrm{breaths} / \mathrm{min}$, oxygen saturation of $99 \%$ on room air, heart rate of 135 beats $/ \mathrm{min}$, and blood pressure of $95 / 51 \mathrm{mmHg}$.

The physical examination revealed a sick-appearing patient, with periorbital edema and non-exudative conjunctivitis, dry cracked lips, (See Figure 1), generalized non-pruritic macular erythematous skin rash, and erythematous edema affecting the extremities (See Figure 2). The pharynx was hyperemic, without any notably palpable lymphadenopathy. He had clear lungs to auscultation. The patient was tachycardic, without any murmurs to auscultation. The extremities were warm and the capillary refill time was of $2 \mathrm{~s}$. The abdominal palpation did not reveal any tenderness.

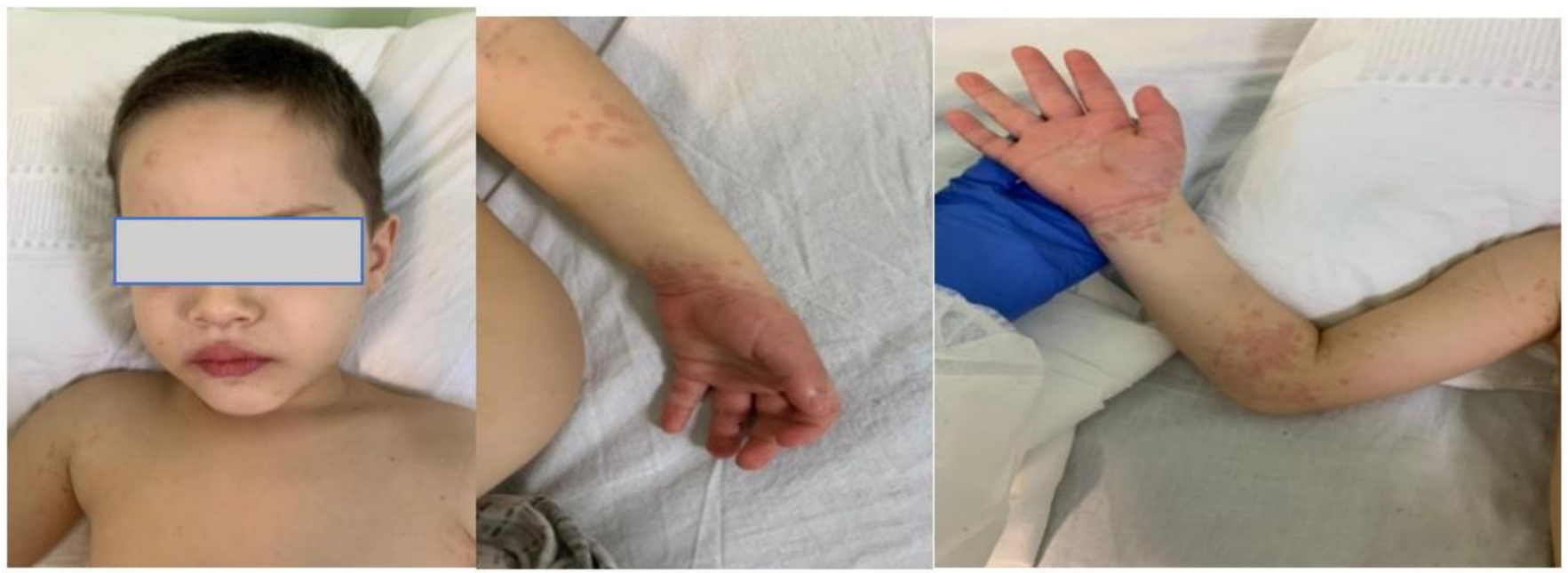

Figure 1. Periorbital edema. Cracked lips. Upper extremity edema and erythema.

Of the imaging analysis, the chest X-ray was unremarkable. The abdominal ultrasonography revealed a few mesenteric lymph nodes with a maximum diameter of 23/14 $\mathrm{mm}$ and $5 \mathrm{~mm}$ of free fluid in the recto-vesical pouch. The echocardiography did not reveal any coronary modifications and the electrocardiogram was normal.

Due to the clinical presentation (fever, conjunctivitis, macular erythematous rash, erythematous burning, and swollen lips, peripheral edema) and the results of laboratory tests, the diagnosis of vasculitis was suspected, including KD. In the absence of prolonged fever, absence of lymphadenopathies, and echocardiography without any coronary abnormalities, KD was excluded.

The significant inflammatory syndrome (C-reactive protein-CRP-186.11 mg/dL, procalcitonin-413.9 $\mathrm{ng} / \mathrm{mL}$, ferritin-218 $\mathrm{ng} / \mathrm{mL}$ ), the high level of interleukin-6 
(IL-6=31.51 pg/mL), and the elevated D-dimer levels $(1.96 \mu \mathrm{g} / \mathrm{mL})$, raised the suspicion of a multisystem inflammatory syndrome post-COVID19 infection.(See Table 1) The immunochromatographic detection of SARS-CoV-2 serum antibodies was positive for immunoglobulin $\mathrm{G}(\operatorname{IgG})$ and negative for immunoglobulin $\mathrm{M}(\mathrm{IgM})$, suggesting a previous SARS-CoV-2 infection.

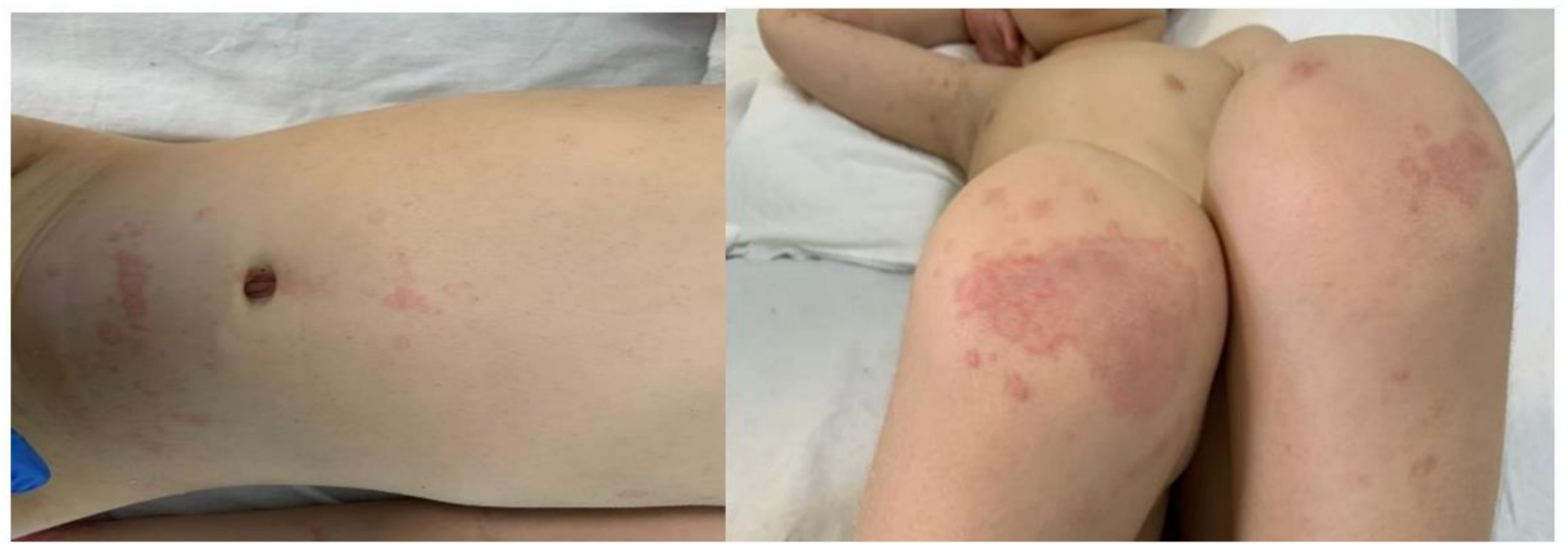

Figure 2. Maculo-erythematous skin rash. (All the images have parental permission).

Table 1. Case 1-Basal and after treatment laboratory parameters.

\begin{tabular}{|c|c|c|c|}
\hline & Before Treatment & After Treatment & Normal Range \\
\hline \multicolumn{4}{|c|}{ Complete blood count } \\
\hline White blood cells count & 12.12 & 10.62 & $5.50-15.50 \times 10^{3} / \mu \mathrm{L}$ \\
\hline Lymphocytes & 1.2 & 2.14 & $2-8 \times 10^{3} / \mu \mathrm{L}$ \\
\hline Neutrophils & 10.38 & 7.42 & $1.5-8.5 \times 10^{3} / \mu \mathrm{L}$ \\
\hline Thrombocytes & 94000 & 554000 & $150.000-450.000 / \mu \mathrm{L} \mathrm{mm}$ \\
\hline $\mathrm{Hb}$ & 13.10 & 12.3 & $11-14 \mathrm{~g} / \mathrm{dL}$ \\
\hline \multicolumn{4}{|c|}{ Rheumatology } \\
\hline C-reactive protein & 186.11 & 0.31 & $0-5 \mathrm{mg} / \mathrm{L}$ \\
\hline Procalcitonin & 413.9 & 0.16 & $<0.05 \mathrm{ng} / \mathrm{mL}$ \\
\hline Ferritin & 218 & & $4-67 \mathrm{ng} / \mathrm{mL}$ \\
\hline IL-6 & 31.51 & & $<7 \mathrm{pg} / \mathrm{mL}$ \\
\hline LDH & 251 & 223 & $120-300 \mathrm{U} / \mathrm{L}$ \\
\hline \multicolumn{4}{|c|}{ Myocardium function } \\
\hline PT & 22.1 & 15.5 & $11.3-15.6 \mathrm{~s}$ \\
\hline APPT & 38.2 & 29.5 & $24-37 \mathrm{~s}$ \\
\hline INR & 1.7 & 1.17 & $0.84-1.2$ \\
\hline D-dimers & 1.96 & 0.49 & $0-0.5 \mu \mathrm{g} / \mathrm{mL}$ \\
\hline Troponin $\mathrm{T}$ & $<40$ & $<40$ & $<40 \mathrm{ng} / \mathrm{mL}$ \\
\hline NT proBNP & 200 & 187 & $<125 \mathrm{pg} / \mathrm{mL}$ \\
\hline CK & 32 & 15 & $7-149 \mathrm{U} / \mathrm{L}$ \\
\hline \multirow{2}{*}{\multicolumn{4}{|c|}{ Kidney function }} \\
\hline & & & \\
\hline Creatinine & 0.39 & 0.29 & $<0.47 \mathrm{mg} / \mathrm{dL}$ \\
\hline BUN & 30.7 & 29.2 & $<39 \mathrm{mg} / \mathrm{dL}$ \\
\hline \multicolumn{4}{|c|}{ Ionogram } \\
\hline $\mathrm{Na}^{+}$ & 129 & 136.3 & $138-145 \mathrm{mmol} / \mathrm{L}$ \\
\hline $\mathrm{K}^{+}$ & 3.97 & 4.45 & $3.5-5.1 \mathrm{mmol} / \mathrm{L}$ \\
\hline \multicolumn{4}{|c|}{ Liver function } \\
\hline TGO & 23.5 & 27.4 & $2-48 \mathrm{U} / \mathrm{L}$ \\
\hline TGP & 27.1 & 30.5 & $2-29 \mathrm{U} / \mathrm{L}$ \\
\hline Albuminemia & 3.35 & 3.75 & $3.8-5.4 \mathrm{~g} / \mathrm{dL}$ \\
\hline Proteinemia & 5.27 & 6.2 & $6-8 \mathrm{~g} / \mathrm{dL}$ \\
\hline \multicolumn{4}{|c|}{ Infectious disease } \\
\hline Blood cultures & Negative & & Negative \\
\hline Urine culture & Negative & & Negative \\
\hline PCR SARS-CoV-2 & Negative & & Negative \\
\hline IgM SARS-CoV-2 & Negative & & Negative \\
\hline IgG SARS-CoV-2 & Positive & & Negative \\
\hline
\end{tabular}


This clinical pattern represents a new phenomenon affecting previously asymptomatic children with SARS-CoV-2 infection manifesting as a hyperinflammatory syndrome with multiorgan involvement similar to Kawasaki disease [15].

The diagnosis of a pediatric multisystem inflammatory syndrome associated with SARS-CoV-2 infection was established, the patient fulfilling the Center for Disease Control (CDC) definition criteria (See Table 2).

Table 2. CDC diagnostic criteria [16].

- $\quad$ Age $<21$ years

- $\quad$ Fever $\geq 24 \mathrm{~h}\left(>38^{\circ} \mathrm{C}\right.$ or subjective fever $)$

- Clinically severe disease necessitating hospitalization

- Laboratory tests suggesting inflammation (CRP, ESR, procalcitonin, fibrinogen, D-dimer, LDH, IL-6, ferritin, hypoalbuminemia, lymphopenia, neutrophilia)

- $\quad \geq 2$ systems involved (cardiac, respiratory, renal, neurological, dermatologic, hematologic, gastrointestinal) AND

No alternative plausible diagnoses AND

Positive for current or recent SARS-CoV-2 infection (RT-PCR, antigen test, serology or Exposure to a suspected or confirmed COVID19 person in the last 4 weeks)

Since clinical presentation and the laboratory findings resembled KD, we decided to start the management of the case based on KD treatment principles. The patient received intravenous fluid resuscitation for 5 days, intravenous immunoglobulin $(400 \mathrm{mg} /$ day for 5 days), corticosteroids ( $2 \mathrm{mg} / \mathrm{kg} /$ day, with decreasing dose, for 13 days) and empirical broad-spectrum antibiotics (Meropenem for 12 days and Targocid for 14 days) according to the MIS-C treatment guideline [16-18]. Symptomatology and laboratory tests slowly improved during hospitalization, with the remission of fever, rash, peripheral edema, conjunctivitis, normalization of the coagulogram, and the decrease of inflammatory markers values. The outcome was favorable, the patient did not have any cardiovascular complications even if he was at high risk.

\subsection{Case Presentation \#2}

We present the case of a 15-year-old male patient transferred to our clinic for fever, vomiting, and chest pain.

The history of presenting complaint includes fever $\left(40^{\circ} \mathrm{C}\right)$, vomiting and somnolence, started 6 days before hospitalization. The patient received at-home treatment prescribed by the general practitioner consisting of antibiotics, antipyretics, and antiemetics. The clinical state worsened, the patient alleged chest pain and palpitations, so he presented to the territorial hospital. Laboratory tests were performed revealing leukopenia, lymphopenia, thrombocytopenia, an important inflammatory syndrome (CRP $=235 \mathrm{mg} / \mathrm{L})$, and an elevated brain natriuretic peptide value (BNP) of $344 \mathrm{pg} / \mathrm{mL}$. The electrocardiogram (ECG) was suggestive for atrial flutter (See Figure 3). The chest radiography showed aspects of peribronchovascular interstitial lung edema (See Figure 4). The patient was transferred in our clinic.

The initial vital signs included fever $\left(38.7^{\circ} \mathrm{C}\right.$ degrees), tachypnea (respiratory rate of 35 breaths/ $\mathrm{min}$ ), hypoxemia (oxygen saturation of $90-93 \%$ on room air), tachycardia (heart rate of 130 beats $/ \mathrm{min})$, and normal blood pressure $(100 / 67 \mathrm{mmHg})$.

The clinical examination revealed a sick appearing patient, conscious, afebrile at the moment, without any rash or lymphadenopathies. He had diminished vesicular murmur to the bases, tachypnea, but no rales. He was tachycardic (130-150 bpm), without any cardiac murmur and he complained of chest pain. The time of capillary refill was $<2 \mathrm{~s}$. He had nausea without vomiting and he alleged diffuse pain to abdominal palpation. 


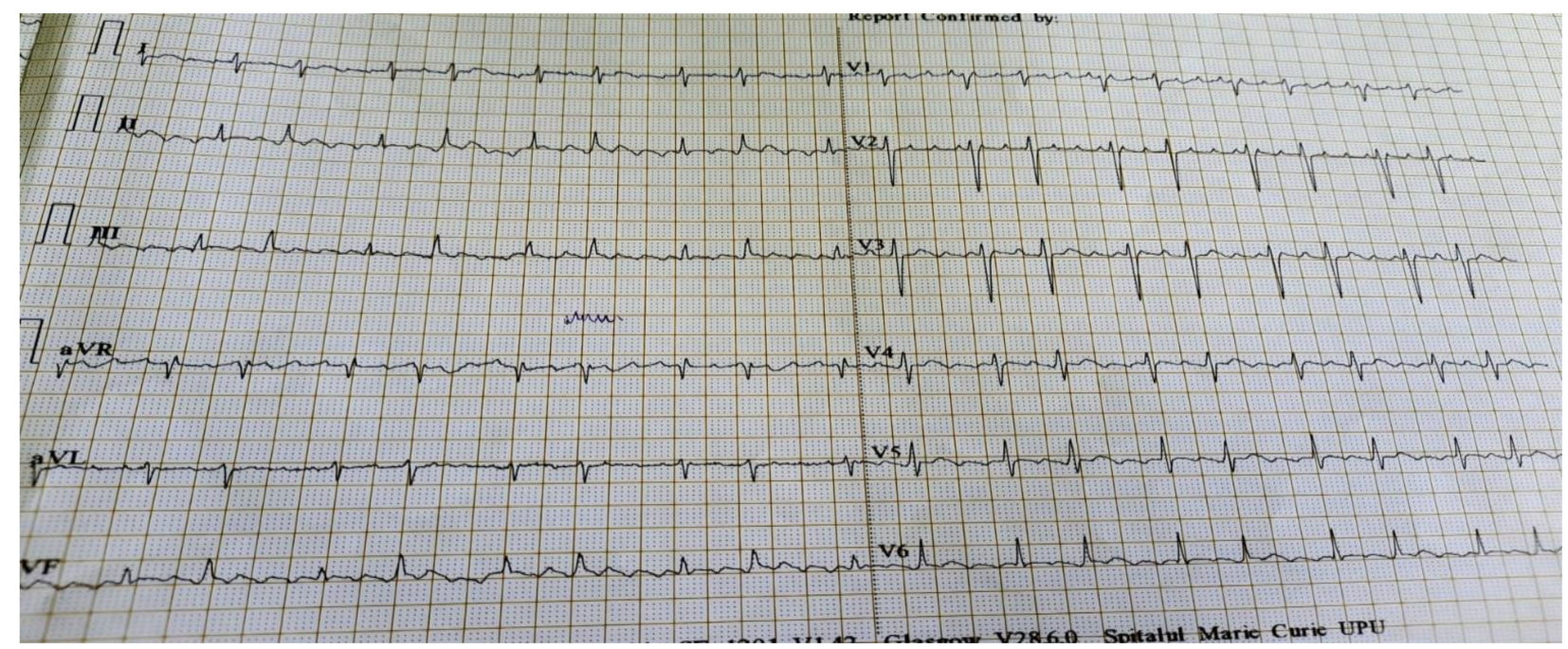

Figure 3. ECG suggestive for atrial flutter with an atrial rate of 300 beats per min (bpm). Atrioventricular conduction rate is variable at 2:1 and 3:1. Therefore, the ventricular rate ranges from 100-150 bpm.

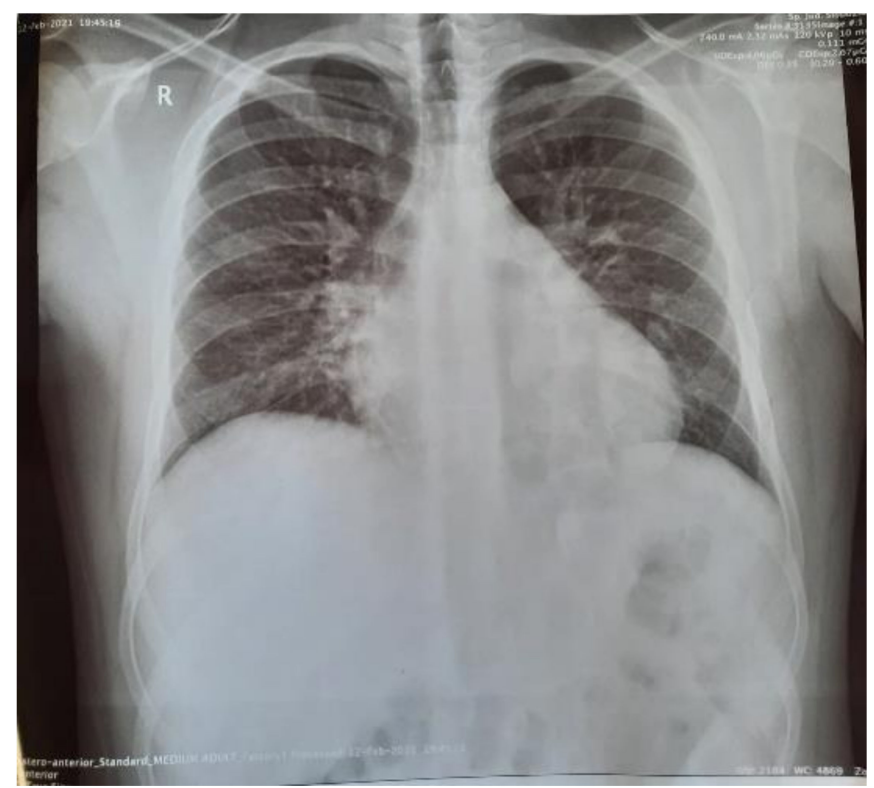

Figure 4. Chest radiography suggestive for aspects of peribronchovascular interstitial edema.

The laboratory tests show normal white blood cell count, lymphopenia, thrombocytopenia and increased values of inflammatory markers (CRP-274.53 mg/L, erythrocyte sedimentation rate-ESR-47mm/L, procalcitonin-2.04 ng $/ \mathrm{mL}$, IL-6- $113.9 \mathrm{pg} / \mathrm{mL}$, ferritin$3331 \mathrm{ng} / \mathrm{mL}$, fibrinogen $555 \mathrm{mg} / \mathrm{dL}$ ) (See Table 3).

The NT-proBNP was elevated $(6421 \mathrm{pg} / \mathrm{mL})$ and the troponin T, creatine kinase (CK) and CK-MB were normal. The D-dimers were positive $(2.38 \mu \mathrm{g} / \mathrm{mL})$, and the coagulogram showed a prolonged partial thromboplastin time (PTT $43.2 \mathrm{~s}$ ), suggesting consumptive coagulopathy. Increased transaminases and the gamma-glutamyl-transpeptidase (GGT) revealed liver dysfunction. The elevated levels of serum creatinine concentration $(1.28 \mathrm{mg} / \mathrm{dL})$, the serum urea $(76.5 \mathrm{mg} / \mathrm{dL})$, and proteinuria $(0.68 \mathrm{~g} / 24 \mathrm{~h})$ suggested renal involvement. The ECG was suggestive for atrial flutter (atrial rate of 300 beats $/ \mathrm{min}$, ventricular rate of 100-150 bpm, 3:1-2:1 atrioventricular conduction). The echocardiography revealed mild depression of left and right ventricular function (left ventricular ejection fraction of $50 \%$ and right ventricular ejection fraction of $45 \%$ ), small mitral and tricuspidian regurgitation, and a small pericardial effusion. 
Table 3. Case 2-Basal and after treatment laboratory parameters.

\begin{tabular}{|c|c|c|c|}
\hline & Initial Results & After Treatment & Reference Values \\
\hline \multicolumn{4}{|c|}{ Complete Blood Count } \\
\hline White blood cells count & 4.77 & 12.92 & $4.50-13 \times 10^{3} / \mu \mathrm{L}$ \\
\hline Lymphocytes & 0.79 & 1.44 & $1.5-6.5 \times 10^{3} / \mu \mathrm{L}$ \\
\hline Neutrophils & 3.64 & 10.85 & $1.8-8 \times 10^{3} / \mu \mathrm{L}$ \\
\hline Platelets & 114,000 & 419,000 & $150.000-450.000 / \mu \mathrm{L} \mathrm{mm}^{3}$ \\
\hline Hemoglobin & 11.9 & 13.8 & $11.7-16.6 \mathrm{~g} / \mathrm{dL}$ \\
\hline \multicolumn{4}{|c|}{ Rheumathologic } \\
\hline C-reactive protein & 274.53 & 0.59 & $0-5 \mathrm{mg} / \mathrm{L}$ \\
\hline ESR & 47 & 6 & $2-15 \mathrm{~mm} / \mathrm{h}$ \\
\hline Procalcitonin & 2.04 & 0.05 & $<0.05 \mathrm{ng} / \mathrm{mL}$ \\
\hline Ferritin & 3331 & 168 & $14-152 \mathrm{ng} / \mathrm{mL}$ \\
\hline IL-6 & 113.9 & 1.5 & $<7 \mathrm{pg} / \mathrm{mL}$ \\
\hline LDH & 324 & 239 & $135-225 \mathrm{U} / \mathrm{L}$ \\
\hline \multicolumn{4}{|c|}{ Cardiovascular } \\
\hline PT & 15.6 & 12.2 & $11.3-15.6 \mathrm{~s}$ \\
\hline APPT & 43.2 & 25 & $24-37 \mathrm{~s}$ \\
\hline INR & 1.18 & 0.91 & $0.84-1.2$ \\
\hline Fibrinogen & 555 & 182 & $160-390 \mathrm{mg} / \mathrm{dL}$ \\
\hline D-dimers & 2.38 & 0.27 & $0-0.5 \mu \mathrm{g} / \mathrm{mL}$ \\
\hline CK & 95 & 87 & $7-270 \mathrm{U} / \mathrm{L}$ \\
\hline CK-MB & 13.9 & 26.9 & $7-25 \mathrm{U} / \mathrm{L}$ \\
\hline Troponin $\mathrm{T}$ & $<40$ & $<40$ & $<40 \mathrm{ng} / \mathrm{mL}$ \\
\hline NT-proBNP & 6421 & 260 & $<125 \mathrm{pg} / \mathrm{mL}$ \\
\hline \multicolumn{4}{|c|}{ Renal } \\
\hline Creatinine & 1.28 & 0.57 & $<1.2 \mathrm{mg} / \mathrm{dL}$ \\
\hline BUN & 76.5 & 41.5 & $<39 \mathrm{mg} / \mathrm{dL}$ \\
\hline \multicolumn{4}{|c|}{ Ionogram } \\
\hline $\mathrm{Na}^{+}$ & 137.6 & & $138-145 \mathrm{mmol} / \mathrm{L}$ \\
\hline $\mathrm{K}^{+}$ & 3.76 & & $3.5-5.1 \mathrm{mmol} / \mathrm{L}$ \\
\hline \multicolumn{4}{|c|}{ Hepatic } \\
\hline TGO & 60.3 & 26.9 & $2-48 \mathrm{U} / \mathrm{L}$ \\
\hline TGP & 60 & 145.3 & $2-29 \mathrm{U} / \mathrm{L}$ \\
\hline GGT & 107 & 87 & $3-29 \mathrm{U} / \mathrm{L}$ \\
\hline Albuminemia & 3.17 & 3.51 & $3.2-4.5 \mathrm{~g} / \mathrm{dL}$ \\
\hline Proteinemia & 6.27 & 6.26 & $6-8 \mathrm{~g} / \mathrm{dL}$ \\
\hline \multicolumn{4}{|c|}{ Infectious } \\
\hline Blood cultures & Negative & & Negative \\
\hline Urine culture & Negative & & Negative \\
\hline Influenza $\mathrm{A}+\mathrm{B}$ antigen test & Negative & & Negative \\
\hline Quantiferon TB Gold test & Negative & & Negative \\
\hline PCR SARS-CoV-2 & Negative & & Negative \\
\hline IgM SARS-CoV-2 & Negative & & Negative \\
\hline IgG SARS-CoV-2 & Positive & & Negative \\
\hline
\end{tabular}

The abdominal echography was unremarkable, and the thoracic-abdominal computer tomography (CT) scan showed interstitial lung edema, distributed bilaterally on the bases, 
bilateral pleural effusion ( $10 \mathrm{~mm}$ on the left side, $12 \mathrm{~mm}$ on the right side), a small pericardial effusion and cardiomegaly, with a cardiothoracic ratio of 0.6 , without any abnormalities of the liver or spleen (See Figures 5-7).

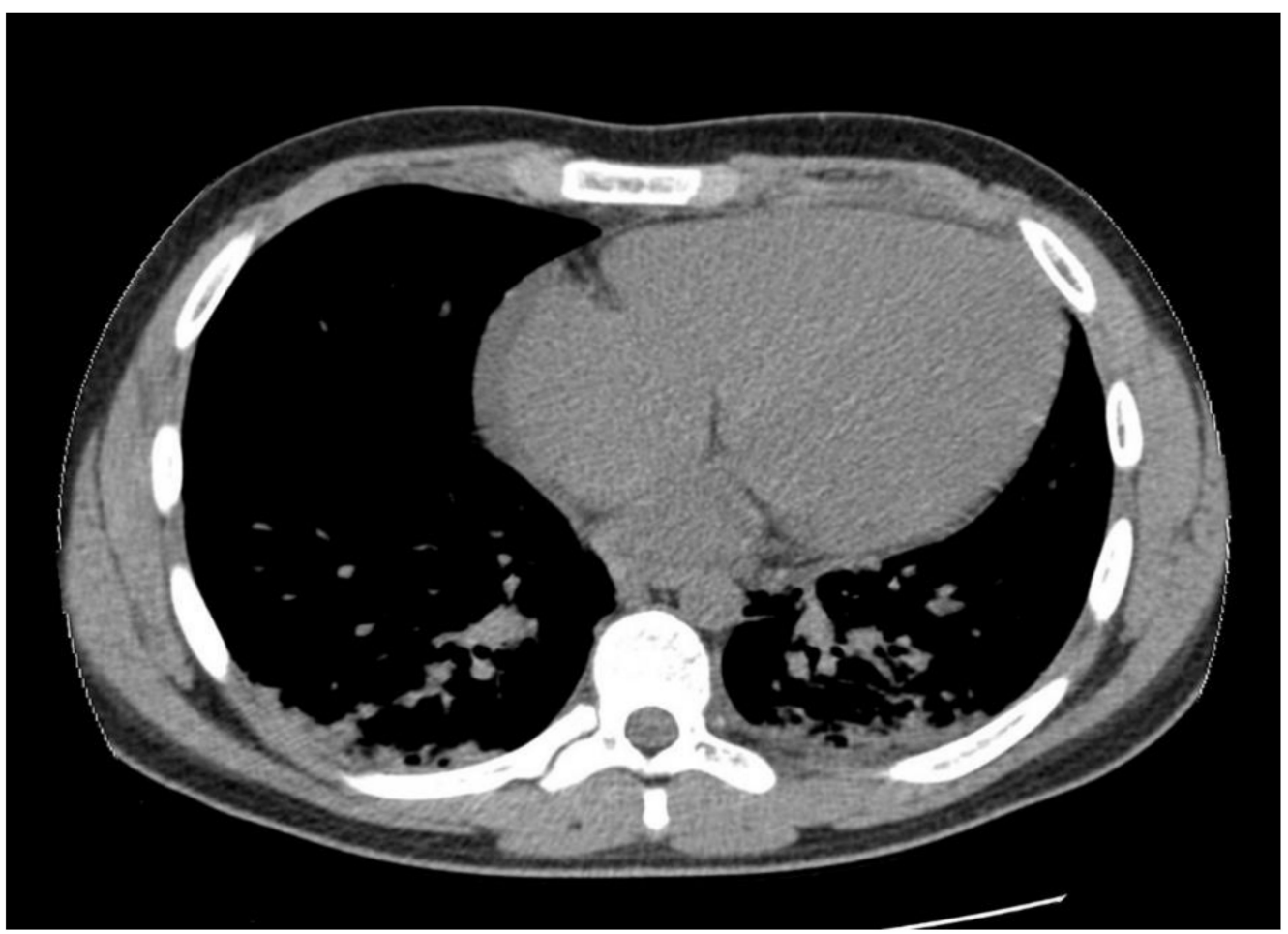

Figure 5. Increased cardiothoracic ratio. Pericardial effusion.

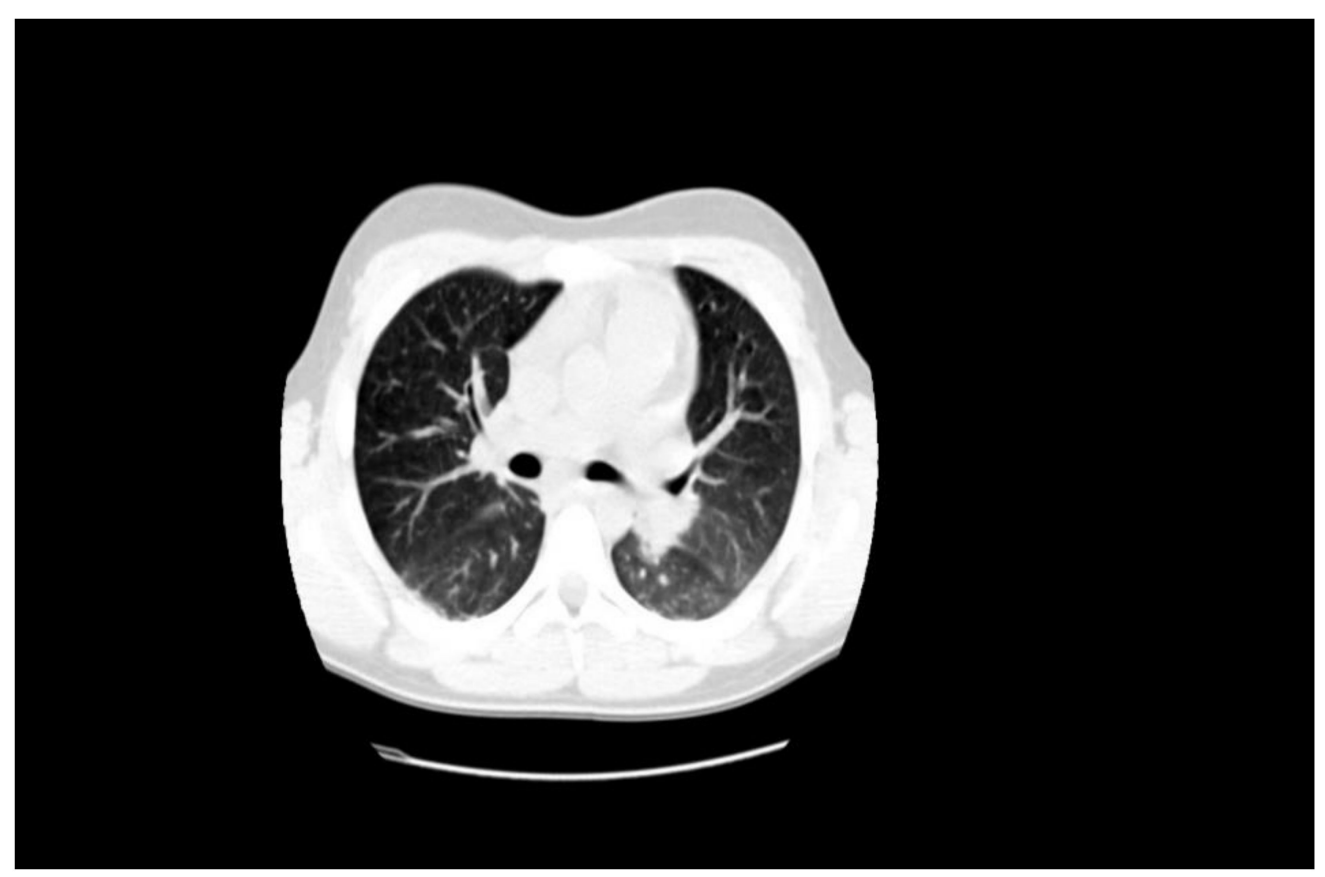

Figure 6. Interstitial edema in congestive heart failure. 




Figure 7. Interstitial edema in congestive heart failure. Small bilateral pleural effusion.

The pericardial effusion, bilateral pleural effusion, along with the ventilation disorders described on the echocardiography and CT scan, are imaging findings demonstrating the congestive heart failure that appeared as a complication of the atrial flutter.

The atrial flutter is very unusual in adolescents, and this may be an indicator of a viral infection or sepsis associated with an exaggerated immune response that can cause myocardial inflammation and, consequently, arrhythmias [15,17,19]. Blood cultures and urine cultures were negative, as were serology for Influenza Virus and Mycobacterium tuberculosis.

From the family history, we found that both grandmother and mother had respiratory infection 1 month ago. Furthermore, the patient alleged anosmia and ageusia during the same period. Considering his history and the actual epidemiological context, he was tested for SARS-CoV-2 infection (polymerase chain reaction-PCR and IgM and IgG antibodies), with negative PCR test result and positive results for IgG antibodies. The MIS-C diagnosis was established using the CDC criteria (see Table 2).

Due to the clinical presentation with cardiac complications, this case was classified as severe and the treatment administered was accordingly to the MIS-C treatment guidelines [15,18].

The priority was the sinus rhythm restoration. A 50 Joules electrical shock was applied under sedation, followed by antiarrhythmic therapy (Amiodarone $400 \mathrm{mg}$ / day for 5 days, then $200 \mathrm{mg}$ /day for 14 days) with a significant improvement in cardiac performance. The treatment of the inflammation consisted in administration of corticotherapy $(2 \mathrm{mg} / \mathrm{kg} /$ day for 7 days, and progressively decreasing doses for 14 days), intravenous immunoglobulins $20 \mathrm{~g} /$ day for 1 day, followed by recombinant IL-1-receptor antagonist (IL1RA) Anakinra $100 \mathrm{mg} /$ day for 7 days. The patient received also antibiotherapy (Ceftriaxon $2 \mathrm{~g} /$ day) for 11 days and thromboprophylaxy (Enoxaparine $40 \mathrm{mg} /$ day) for 14 days, with clinical and paraclinical improvement. He did not experience another episode of atrial flutter, the fever subsided, the oxygen saturation maintained in normal ranges, the values of 
inflammatory markers decreased, also the cardiac enzymes and the echocardiography showed improvement of the cardiac function.

\section{Literature Review}

\subsection{Coronavirus Disease 2019}

COVID-19 is an illness produced by SARS-CoV-2 infection, described to affect mostly adults and only a small proportion of children [18-20]. Almost $90 \%$ of children and adolescents were described to have an asymptomatic or mild form of the disease that does not require any medical intervention $[4,5,19]$. (p. 19). The mortality rate in pediatric patients is $<1 \%[8,21]$. Despite this favorable outcome, in April 2020, a group of clinicians in the UK reported the first cases of hyper inflammation, fever, and cardiovascular shock in 8 previously healthy children [2,8]. Of these patients, all had a significant inflammatory syndrome and negative tests for an acute SARS-CoV-2 infection, although many had recent COVID-19 contact [8]. The clinical presentation of these patients was related to other pediatric inflammatory syndromes such as Kawasaki disease and toxic shock syndrome [20-22]. Firstly, this hyperinflammatory syndrome was considered to be a Kawasaki variant [8].

\subsection{Kawasaki Disease}

Kawasaki disease is a self-limited childhood vasculitis affecting the small and mediumsized vessels, including the coronary arteries [4,23]. In the absence of treatment, almost a quarter of children develop coronary artery aneurysms [24]. The etiology remains unknown, but recent or active infections in genetically predisposed children have been incriminated [2,8]. KD is found worldwide, the incidence being higher in Asian individuals and affecting children less than 5 years old [4]. The clinical manifestations required for the diagnosis of classical KD include high fever, unresponsiveness to antipyretics lasting for more than 5 days, and at least 4 of 5 of the following criteria: bilateral non-exudative conjunctivitis, polymorphous generalized rash, cervical lymphadenopathy $(<1.5 \mathrm{~cm})$, peripheral extremity changes (erythema of palms, edema of hands and feet, peeling of fingers or toes) and oropharyngeal changes (strawberry tongue, erythematous cracking lips) [24]. Sometimes, besides fever lasting for more than 4 days, only 2 or 3 of the other clinical criteria can be met. The association of fever $>4$ days with 2 or 3 criteria diagnoses an incomplete form of KD. The most severe variant of KD is the KD shock syndrome associated with hypotension unresponsive to treatment [25]. In order to prevent coronary complications, intravenous immunoglobulin and aspirin treatment must be initiated promptly [8].

\subsection{MIS-C}

The CDC defines MIS-C as a syndrome that affects individuals aged $<21$ years positive for current or recent SARS-CoV-2 infection (PCR, serology, or antigen test) or considered close contacts to suspected or confirmed COVID19 cases within the 4 weeks prior to the onset of symptoms which develop fever $\geq 38.0^{\circ} \mathrm{C}$ for more than one day and have laboratory evidence of inflammation (high levels of CRP, ESR, procalcitonin, fibrinogen, lactate dehydrogenase-LDH, IL-6, d-dimer, ferritin, neutrophilia, lymphopenia, hypoalbuminemia), and evidence of clinically severe illness requiring hospitalization, with multisystem $(\geq 2)$ organ involvement (cardiac, renal, respiratory, hematologic, gastrointestinal, dermatologic or neurological); in the absence of other plausible diagnoses [16].

By comparison with the rate of SARS-CoV-2 infection in patients aged <21-year-old (322 in 100,000), MIS-C is rarely seen (2 in 100,000) [25,26]. However, the awareness of this new syndrome must be raised due to its polymorphous presentation and its possible lethal complications.

Initially, MIS-C presentation appears similar to KD or toxic shock syndrome, the symptomatology including fever, rash, conjunctivitis, and sometimes shock if the myocardium is involved [6]. Compared to KD, gastrointestinal symptoms are more common in MISC. In order to prevent complications like coronary aneurysms and myocardial damage, 
the diagnosis should be established quickly and the treatment administered immediately (See Figure 8).

A proposal for diagnostic design in Multisystem Inflammatory Syndrome in Children - MIS-C

Clinical suspicion

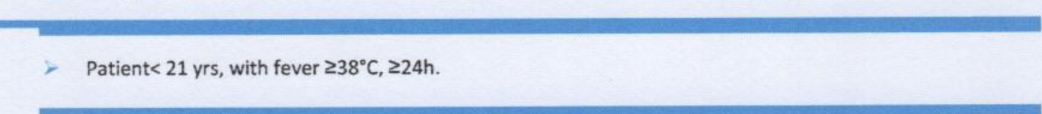

Two or more of the following clinical features:

- Rash (polymorphic, maculopapular or petechial, but not vesicular)

- Mucocutaneous signs (oral, hands/feet)

- Peripheral edema (hands/feet)

- Bilateral non-purulent conjunctivitis

- Gastrointestinal symptoms:(abdominal pain,vomiting, diarrhea)

- Lymphadenopathy

One or more of the following:

- Respiratory symptoms

- Features of myocardial disfunction, pericarditis or coronary abnormalities

- Hypotension/shock ; evidence of coagulopathy

- Severe end-organ involvement, including neurological or renal disease.

- Positive for COVID-19 infection or close contact with COVID -19 positive within the 4 weeks

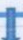

Initial work-up:CBC, CRP, ESR, SARS-COV-2 PCR and/or serologies; complete metabolic evaluation ( $\mathrm{Na}, \mathrm{K}, \mathrm{CO} 2, \mathrm{Cl}$, BUN, $\mathrm{Cr}$, glucose, albumin, total protein, AST, ALT, bilirubin).

Complete evaluation Procalcitonin, ferritin, fibrinogen, PT, PTT, D-dimer,

NT-pro BNP, troponin T,

LDH, triglycerides,

cytokine panel (IL6, TNF, IL10)

SARS- COV-2 serology (IgM, IgG, IgA)

ECG, Echocardiogram
Do labs show all of the following?

1. CRP $\geq 5 \mathrm{mg} / \mathrm{dL}$ OR ESR $\geq 40 \mathrm{~mm} / \mathrm{h}$

2. At least 1 of the following

- ALC $<10^{3} / \mu \mathrm{l}$

- Platelets $<150 \times 10^{3} / \mu \mathrm{L}$

- $\mathrm{Na}<135 \mathrm{mmol} / \mathrm{L}$

- Neutrophilia

- Hypoalbuminemia

Additional workup:

- Chest $X$ ray, $C T$ chest.

- Pediatric Intensive Care Unit (PICU) if any signs of cardiac shock/hypotension,

high respiratory support, or concern for rapid progression.

References:

1. Clinical Guidance for Pediatric Patients with Multisystem Inflammatory Syndrome in Children (MIS-C) Associated with SARSCoV-2 and Hyperinflammation in COVID-19. Published June 18, 2020. https://www.rheumatology.org/Portals/O/Files/ACRCOVID-19-Clinical-Guidance-Summary-MIS-C-Hyperinflammation.pdf.

2. Evelina London Clinical Guideline https://pubmed.ncbi.nim.nih.gov/33277976/

3. Jonat B, Gorelik M, Boneparth A, Geneslaw AS, Zachariah P, Shah A, et al. Multisystem Inflammatory Syndrome in Children Associated With Coronavirus Disease 2019 in a Children's Hospital in New York City. Pediatr Crit Care Med. 2020;

4. Henderson LA, Canna SW, Friedman KG, Gorelik M, Lapidus SK, Bassiri H, et al. American College of Rheumatology Clinical Guidance for Pediatric Patients with Multisystem Inflammatory Syndrome in Children (MIS-C) Associated with SARS-CoV-2 and Hyperinflammation in COVID-19.

Figure 8. A proposal for diagnostic design in Multisystem Inflammatory Syndrome in Children. 
Until this moment, there does not exist any standardized treatment protocol. The treatment prescribed in the reported case series was similar to the treatment of KD (intravenous immunoglobulin, low-dose aspirin) along with corticosteroids and broad-spectrum antibiotics. In patients with circulatory shock, vasoactive support and fluid resuscitation were required $[1,2,4]$.

\subsection{KD versus MIS-C}

All the case series reported in London, then Bergamo, New York City, and Paris helped to define the MIS-C and to differentiate it from KD. The resemblance between KD and MIS-C is that they have various clinical presentations and none of them are associated with a pathognomonic diagnostic test [2,27]. The differences between the two entities consist in the race most commonly involved (the Asian race in KD and the African in Kawasaki-like syndrome), the males are more frequently affected in MIS-C, the age of onset (KD appears mostly in <5-year-old children, and MIS-C in children >4-year-old and adolescents), the symptomatology, MIS-C being associated mostly with an incomplete form of KD [4,28]. Furthermore, a more frequent gastrointestinal involvement and a higher risk of cardiovascular complications in MIS-C (76\%) was found than in KD (26-40\% in the absence of the treatment and $<3 \%$ if immunoglobulins are administered) like coronary aneurysms, myocarditis with cardiogenic shock $[9,15]$. Additionally, the laboratory tests reveal different abnormalities (in MIS-C, the blood count reveals frequently leukopenia with neutrophilia and lymphopenia, and thrombocytopenia, in KD lymphopenia being rare) $[4,8,29]$. The level of inflammatory markers is much more elevated in MIS-C than in KD. Concerning the treatment, patients with MIS-C may present greater resistance to intravenous immunoglobulin [4].

\subsection{COVID19 and Atrial Flutter}

Most MIS-C cases associate cardiovascular complications, such as myocardial dysfunction, myocarditis, coronary dilation or aneurysm, atrio-ventricular block, or arrhythmias [30]. Arrhythmias are poorly described in children and may have nonspecific manifestation such as premature ventricular beats, premature atrial beats, changes of the ST segment, or QT prolongation [16,30]. Atrial fibrillation and atrial flutter are rarely reported [30,31]. In adult patients with COVID19, atrial fibrillation and atrial flutter incidence are also decreased (10\%) [32]. Atrial flutter development in adolescents may be an indicator of a viral infection or sepsis associated with an exaggerated immune response who can cause myocardial inflammation and, as a consequence, arrhythmias [31] (p. 2). Although rare, the onset of atrial flutter is associated with high rate of mortality and poor outcomes, so it needs rapid recognition and intervention $[17,32]$.

\section{Discussion}

Almost $20 \%$ of children infected with SARS-CoV-2 are asymptomatic [33]. Independent of the clinical syndrome, the MIS-C and non-MIS-C patients develop an immunological response consisting of high levels of $\operatorname{IgG}$ and immunoglobulin A (IgA) and absence or low levels of circulating IgM [34,35]. The number of IgG levels increased over time after the onset of symptoms and has a few weeks of stability, this durable response being demonstrated in MIS-C patients. The IgA levels exceed the levels found in adults' convalescent plasma and may explain the gastrointestinal symptoms in children [34].

Because MIS-C appears weeks later after the SARS-CoV-2 infection, it is supposed that an aberrant immune response is involved [26]. The serum profiling reveals high levels of IL-1 $\beta$, IL-6, IL-8, IL-10, IL-17 and gamma interferon (IFN- $\gamma$ ) and normal or low ranges of alpha tumor necrosis factor (TNF- $\alpha$ ) [30,31]. MIS-C, compared with KD, have endothelial dysfunction associated with mild and transient coronary dysfunction, without any morphological changes as aneurysms. This type of coronary dilation is similar to the febrile onset of juvenile systemic arthritis [32-35]. 
In $\mathrm{KD}$, the pathophysiological mechanism includes the production of autoantibodies as a response to an acute viral infection. This response involves mostly the IgA producing plasma cells. In the artery walls, IgA producing cells and neutrophils were found. By comparison with MIS-C, in KD these cells contribute to morphology changes in the arterial wall and destruction of the connective tissue with the development of arterial aneurysms $[30,36,37]$. The serum profiling reveals elevated values of IL-17A, IL-6, C-X-C motif chemokine ligand 10 (CXCL10) and higher values of markers associated with coronary artery disease [30,31].

The similarities and differences of the pathophysiological mechanisms might influence the treatment choices. Intravenous immunoglobulins may neutralize the autoantibodies produced in both diseases. Corticosteroids help to generate general immunosuppression. Due to the high levels of IL-17A, KD secukinumab can be considered. Instead, MIS$\mathrm{C}$ can be treated with anakinra, a recombinant IL-1-receptor antagonist and also with IL-6 antagonists. Anti-TNF- $\alpha$ medicines are not effective due to the normal range of this biomarker [30].

\section{Case Particularities}

The first patient presented an incomplete form of KD (fever $<2$ days, rash, conjunctivitis, peripheral edema and oropharyngeal modifications) and positive IgG antibodies anti-SARS-CoV-2, even though he had not had any symptoms or close contact with a COVID19 individual. He was one of the first patients hospitalized in our clinic for MIS-C. The symptomatology resembled the cases described initially in the literature, but comparatively the patient did not allege any gastrointestinal symptoms [38]. The limitations of the laboratory did not allow us to dose the levels of $\operatorname{IgA}$, which could have explained the absence of gastrointestinal symptoms. The inflammatory markers were incredibly elevated, especially procalcitonin $(413.9 \mathrm{ng} / \mathrm{mL})$, compared to the mean value reported in the literature $30.5 \pm 2.1$ [39]. High levels of inflammatory markers are associated with Kawasaki disease shock syndrome [4]. Ahmed et al. report that $54 \%$ of the MIS-C patients associate cardiac complications with echocardiography modifications, and 50\% develop cardiogenic shock. Moreover, $71 \%$ of patients need hospitalization in the ICU department [39]. Although our patient had a high risk of developing cardiac complications and shock, his evolution was favorable.

The second patient described COVID19-specific symptoms 4 weeks before hospitalization and he was part of a community known to have a high rate of SARS-CoV-2 infection. Although the MIS-C have clinical manifestations of complete KD in $64 \%$ of cases, our patient presented only fever as a KD criteria [19]. Instead, he had more severe manifestations, such as atrial flutter. The atrial flutter is very unusual in adolescents and extremely rare in the literature in MIS-C patients [31,40]. Atrial flutter onset is associated with an elevated risk of mortality, so immediate recognition and treatment are required [32]. We chose to present this case in order to highlight that the symptomatology in adolescents with MIS-C can be more severe, with multiorgan dysfunction, as described in COVID19-related multisystem inflammatory syndrome in adults [41].

\section{Conclusions}

Multisystem inflammatory syndrome in children associated with COVID19 is a rare and severe complication of SARS-CoV-2 infection with polymorphous presentation. To highlight the variability of the clinical presentations, we exposed two cases of MIS-C, a case with Kawasaki-like symptoms and a case with atrial flutter and cardiac involvement. MIS-C must be diagnosed immediately, being a disease that requires aggressive treatment initiated as soon as possible to prevent possible complications (coronary aneurysms, myocarditis, and cardiogenic shock). Initially considered a KD variant, MIS-C may have a worse prognosis than KD so a high degree of vigilance must be maintained during this pandemic.

This report showed that inflammatory markers concentration (CRP, ESR, procalcitonin, ferritin, IL-6, fibrinogen), and D dimers value, can be used as laboratory findings for 
diagnosis, for the appropriate treatment choice, and for monitoring disease improvement in COVID-19 as well. We also encourage further studies to make a prognostic model that includes these biomarkers along with other proven poor prognostic factors in similar cases.

Author Contributions: M.D.I., A.N. and E.C.B. equally contributed to the analysis and interpretation of the data, critically reviewed and revised the manuscript. R.T. and B.D. contributed to the acquirement and interpretation of data, B.D. drafted the initial manuscript. M.B. coordinated and supervised data collection, and critically reviewed and revised the manuscript for important intellectual content. All authors have read and agreed to the published version of the manuscript.

Funding: This research received no external funding.

Institutional Review Board Statement: The research was approved by the Ethics Committee of "Marie Curie" Emergency Children's Hospital.

Informed Consent Statement: Informed consent was obtained from all subjects involved in the study.

Data Availability Statement: Not applicable.

Conflicts of Interest: The authors declare no conflict of interest.

$\begin{array}{ll}\text { Abbreviations } \\ \text { SARS-CoV-2 } & \text { Severe acute respiratory coronavirus 2; } \\ \text { COVID19 } & \text { coronavirus disease 2019; } \\ \text { KD } & \text { Kawasaki disease; } \\ \text { MIS-C } & \text { multisystemic inflammatory syndrome in children; } \\ \text { PIMS-TS } & \text { pediatric multisystem inflammatory syndrome temporally } \\ \text { UK } & \text { associated with SARS-CoV-2 infection; } \\ \text { USA } & \text { United Kingdom; } \\ \text { CRP } & \text { C-reactive protein; } \\ \text { IL-6 } & \text { interleukin-6; } \\ \text { IgG } & \text { immunoglobulin G; } \\ \text { IgM } & \text { immunoglobulin M; } \\ \text { PT } & \text { prothrombin time; } \\ \text { APTT } & \text { activated partial thromboplastin time; } \\ \text { INR } & \text { international normalized ratio; } \\ \text { CK } & \text { creatine kinase; } \\ \text { PCR } & \text { polymerase chain reaction; } \\ \text { ECG } & \text { electrocardiogram; } \\ \text { CDC } & \text { Center for Disease Control; } \\ \text { BNP } & \text { brain natriuretic peptide; } \\ \text { ESR } & \text { erythrocyte sedimentation rate; } \\ \text { NT-proBNP } & \text { N-terminal pro brain natriuretic peptide; } \\ \text { TGO } & \text { glutamic-oxaloacetic transaminase; } \\ \text { TGP } & \text { glutamic pyruvic transaminase; } \\ \text { GGT } & \text { gamma glutamyl transferase; } \\ \text { CT } & \text { computer tomography; } \\ \text { IL1RA } & \text { IL1 receptor antagonist; } \\ \text { LDH } & \text { lactate dehydrogenase; } \\ \text { IgA } & \text { immunoglobulin A; } \\ \text { IFN- } \gamma & \text { gamma interferon; } \\ \text { TNF- } \alpha & \text { alpha tumor necrosis factor; } \\ \text { CXCL10 } & \text { C-X-C motif chemokine ligand 10. } \\ & \end{array}$




\section{References}

1. Verdoni, L.; Mazza, A.; Gervasoni, A.; Martelli, L.; Ruggeri, M.; Ciuffreda, M.; Bonanomi, E.; D’Antiga, L. An outbreak of severe Kawasaki-like disease at the Italian epicentre of the SARS-CoV-2 epidemic: An observational cohort study. Lancet 2020, 395, 1771-1778. [CrossRef]

2. Feldstein, L.R.; Rose, E.B.; Horwitz, S.M.; Collins, J.P.; Newhams, M.M.; Son, M.B.F.; Newburger, J.W.; Kleinman, L.C.; Heidemann, S.M.; Martin, A.A.; et al. Multisystem Inflammatory Syndrome in U.S. Children and Adolescents. N. Engl. J. Med. 2020, 383, 334-346. [CrossRef] [PubMed]

3. COVID-19 Outbreak Live Update. Available online: https://www.worldometers.info/ coronavirus/ (accessed on 14 March 2020).

4. Toubiana, J.; Poirault, C.; Corsia, A.; Bajolle, F.; Fourgeaud, J.; Angoulvant, F.; Debray, A.; Basmaci, R.; Salvador, E.; Biscardi, S.; et al. Kawasaki-like multisystem inflammatory syndrome in children during the covid-19 pandemic in Paris, France: Prospective observational study. BMJ 2020, 369, m2094. [CrossRef] [PubMed]

5. Götzinger, F.; Santiago-García, B.; Noguera-Julián, A.; Lanaspa, M.; Lancella, L.; Carducci, F.I.C.; Gabrovska, N.; Velizarova, S.; Prunk, P.; Osterman, V.; et al. COVID-19 in children and adolescents in Europe: A multinational, multicentre cohort study. Lancet Child Adolesc. Health 2020, 4, 653-661. [CrossRef]

6. Rapid risk assessment: Paediatric inflammatory multisystem syndrome and SARS -CoV-2 infection in children. European Centre for Disease Prevention and Control. 15 May 2020. Available online: https:/ /www.ecdc.europa.eu/en/publications-data/paediatricinflammatory-multisystem-syndrome-and-sars-cov-2-rapid-risk-assessment (accessed on 17 December 2020).

7. PIMS-TS in children. 2020, p. 18. Available online: https://www.ecdc.europa.eu/sites/default/files/documents/covid-19-riskassessment-paediatric-inflammatory-multisystem-syndrome-15-May-2020.pdf (accessed on 17 December 2020).

8. Nelson, C.; Ishimine, P.; Hayden, S.R.; Correia, M.; Wardi, G. Multisystem Inflammatory Syndrome in Children (MIS-C) in an Adolescent that Developed Coronary Aneurysms: A Case Report and Review of the Literature. J. Emerg. Med. 2020, 59, 699-704. [CrossRef] [PubMed]

9. Pouletty, M.; Borocco, C.; Ouldali, N.; Caseris, M.; Basmaci, R.; Lachaume, N.; Bensaid, P.; Pichard, S.; Kouider, H.; Morelle, G.; et al. Paediatric multisystem inflammatory syndrome temporally associated with SARS-CoV-2 mimicking Kawasaki disease (Kawa-COVID-19): A multicentre cohort. Ann. Rheum. Dis. 2020, 79, 999-1006. [CrossRef] [PubMed]

10. Riphagen, S.; Gomez, X.; Gonzalez-Martinez, C.; Wilkinson, N.; Theocharis, P. Hyperinflammatory shock in children during COVID-19 pandemic. Lancet 2020, 395, 1607-1608. [CrossRef]

11. Grimaud, M.; Starck, J.; Levy, M.; Marais, C.; Chareyre, J.; Khraiche, D.; Leruez-Ville, M.; Quartier, P.; Léger, P.L.; Geslain, G.; et al. Acute myocarditis and multisystem inflammatory emerging disease following SARS-CoV-2 infection in critically ill children. Ann. Intensiv. Care 2020, 10, 1-5. [CrossRef]

12. Davies, P.; Evans, C.; Kanthimathinathan, H.K.; Lillie, J.; Brierley, J.; Waters, G.; Johnson, M.; Griffiths, B.; du Pré, P.; Mohammad, Z.; et al. Intensive care admissions of children with paediatric inflammatory multisystem syndrome temporally associated with SARS-CoV-2 (PIMS-TS) in the UK: A multicentre observational study. Lancet Child Adolesc. Health 2020, 4, 669-677. [CrossRef]

13. Dong, Y.; Mo, X.; Hu, Y.; Qi, X.; Jiang, F.; Jiang, Z.; Tong, S. Epidemiology of COVID-19 Among Children in China. Pediatrics 2020, 145, e20200702. [CrossRef]

14. Cokugras, H.; Onal, P. SARS-CoV-2 infection in children. Turk. Arch. Pediatr. 2021, 55, 95-102. [CrossRef] [PubMed]

15. Capone, C.A.; Subramony, A.; Sweberg, T.; Schneider, J.; Shah, S.; Rubin, L.; Schleien, C.; Epstein, S.; Johnson, J.C.; Kessel, A.; et al. Characteristics, Cardiac Involvement, and Outcomes of Multisystem Inflammatory Syndrome of Childhood Associated with severe acute respiratory syndrome coronavirus 2 Infection. J. Pediatr. 2020, 224, 141-145. [CrossRef] [PubMed]

16. CDC. Multisystem Inflammatory Syndrome in Children (MIS-C); Centers for Disease Control and Prevention: Atlanta, GA, USA, 2020. Available online: https://www.cdc.gov/mis-c/hcp/ (accessed on 18 December 2020).

17. Su, J.A.; Weisert, M.A.; Silka, M.J.; Bar-Cohen, Y.; Menteer, J. SARS-CoV-2 infection presenting as sustained atrial flutter and advanced ventricular dysfunction. Clin. Case Stud. Rep. 2020, 3. [CrossRef]

18. Yonker, L.M.; Neilan, A.M.; Bartsch, Y.; Patel, A.B.; Regan, J.; Arya, P.; Gootkind, E.; Park, G.; Hardcastle, M.; John, A.S.; et al. Pediatric Severe Acute Respiratory Syndrome Coronavirus 2 (SARS-CoV-2): Clinical Presentation, Infectivity, and Immune Responses. J. Pediatr. 2020, 227, 45-52.e5. [CrossRef] [PubMed]

19. Felsenstein, S.; Hedrich, C.M. SARS-CoV-2 infections in children and young people. Clin. Immunol. 2020, $220,108588$. [CrossRef] [PubMed]

20. Jones, V.G.; Mills, M.; Suarez, D.; Hogan, C.A.; Yeh, D.; Segal, J.B.; Nguyen, E.L.; Barsh, G.R.; Maskatia, S.; Mathew, R. COVID-19 and Kawasaki Disease: Novel Virus and Novel Case. Hosp. Pediatr. 2020, 10, 537-540. [CrossRef] [PubMed]

21. Akca, U.K.; Kesici, S.; Ozsurekci, Y.; Aykan, H.H.; Batu, E.D.; Atalay, E.; Demir, S.; Sag, E.; Vuralli, D.; Bayrakci, B.; et al. Kawasaki-like disease in children with COVID-19. Rheumatol. Int. 2020, 40, 2105-2115. [CrossRef]

22. Jiang, L.; Tang, K.; Levin, M.; Irfan, O.; Morris, S.K.; Wilson, K.; Klein, J.D.; A Bhutta, Z. COVID-19 and multisystem inflammatory syndrome in children and adolescents. Lancet Infect. Dis. 2020, 20, e276-e288. [CrossRef]

23. Schnabel, A.; Hedrich, C.M. Childhood Vasculitis. Front. Pediatr. 2019, 6. [CrossRef]

24. Kliegman, R.M. Nelson Textbook of Pediatrics; Elsevier: Philadelphia, PA, USA, 2020; p. 15739.

25. Kanegaye, J.T.; Wilder, M.S.; Molkara, D.; Frazer, J.R.; Pancheri, J.; Tremoulet, A.H.; Watson, V.E.; Best, B.M.; Burns, J.C. Recognition of a Kawasaki Disease Shock Syndrome. Pediatrics 2009, 123, e783-e789. [CrossRef] 
26. Levin, M. Childhood Multisystem Inflammatory Syndrome-A New Challenge in the Pandemic. N. Engl. J. Med. 2020, 383, 393-395. [CrossRef] [PubMed]

27. Henderson, L.A.; Canna, S.W.; Friedman, K.G.; Gorelik, M.; Lapidus, S.K.; Bassiri, H.; Behrens, E.M.; Ferris, A.; Kernan, K.F.; Schulert, G.S.; et al. American College of Rheumatology Clinical Guidance for Multisystem Inflammatory Syndrome in Children Associated With SARS-CoV-2 and Hyperinflammation in Pediatric COVID-19: Version 1. Arthritis Rheumatol. 2020, 72, 1791-1805. [CrossRef] [PubMed]

28. Dufort, E.M.; Koumans, E.H.; Chow, E.J.; Rosenthal, E.M.; Muse, A.; Rowlands, J.; Barranco, M.A.; Maxted, A.M.; Rosenberg, E.S.; Easton, D.; et al. Multisystem Inflammatory Syndrome in Children in New York State. N. Engl. J. Med. 2020, 383, 347-358. [CrossRef] [PubMed]

29. Rowley, A.H. Understanding SARS-CoV-2-related multisystem inflammatory syndrome in children. Nat. Rev. Immunol. 2020, 20, 453-454. [CrossRef] [PubMed]

30. Elsevier Enhanced Reader. The Immunology of Multisystem Inflammatory Syndrome in Children with COVID-19. Available online: https:/ / reader.elsevier.com/reader/sd/pii/S0092867420311570?token=C76035267893E8797C4E5344AE39E225D70803 D7F8958176ADACFD03D35AD3889E6DBC9F2884FFBD683311514FD15B16 (accessed on 3 March 2021).

31. Brodsky, N.N.; Ramaswamy, A.; Lucas, C.L. The Mystery of MIS-C Post-SARS-CoV-2 Infection. Trends Microbiol. 2020, 28, 956-958. [CrossRef]

32. Rowley, A.H.; Shulman, S.T.; Arditi, M. Immune pathogenesis of COVID-19-related multisystem inflammatory syndrome in children. J. Clin. Investig. 2020, 130, 5619-5621. [CrossRef]

33. Lu, X.; Zhang, L.; Du, H.; Zhang, J.; Li, Y.Y.; Qu, J.; Zhang, W.; Wang, Y.; Bao, S.; Li, Y.; et al. SARS-CoV-2 Infection in Children. N. Engl. J. Med. 2020, 382, 1663-1665. [CrossRef]

34. Weisberg, S.P.; Connors, T.J.; Zhu, Y.; Baldwin, M.R.; Lin, W.-H.; Wontakal, S.; Szabo, P.A.; Wells, S.B.; Dogra, P.; Gray, J.; et al. Distinct antibody responses to SARS-CoV-2 in children and adults across the COVID-19 clinical spectrum. Nat. Immunol. 2021, 22, 25-31. [CrossRef]

35. Gruber, C.N.; Patel, R.S.; Trachtman, R.; Lepow, L.; Amanat, F.; Krammer, F.; Wilson, K.M.; Onel, K.; Geanon, D.; Tuballes, K.; et al. Mapping Systemic Inflammation and Antibody Responses in Multisystem Inflammatory Syndrome in Children (MIS-C). Cell 2020, 183, 982-995.e14. [CrossRef]

36. Shulman, S.T.; Rowley, A.H. Kawasaki disease: Insights into pathogenesis and approaches to treatment. Nat. Rev. Rheumatol. 2015, 11, 475-482. [CrossRef] [PubMed]

37. Rowley, A.H.; Baker, S.C.; Orenstein, J.M.; Shulman, S.T. Searching for the cause of Kawasaki disease-Cytoplasmic inclusion bodies provide new insight. Nat. Rev. Genet. 2008, 6, 394-401. [CrossRef] [PubMed]

38. Miller, J.; Cantor, A.; Zachariah, P.; Ahn, D.; Martinez, M.; Margolis, K.G. Gastrointestinal Symptoms as a Major Presentation Component of a Novel Multisystem Inflammatory Syndrome in Children That Is Related to Coronavirus Disease 2019: A Single Center Experience of 44 Cases. Gastroenterology 2020, 159, 1571-1574.e2. [CrossRef] [PubMed]

39. Ahmed, M.; Advani, S.; Moreira, A.; Zoretic, S.; Martinez, J.; Chorath, K.; Acosta, S.; Naqvi, R.; Burmeister-Morton, F.; Burmeister, F.; et al. Multisystem inflammatory syndrome in children: A systematic review. EClinicalMedicine 2020, 26, 100527. [CrossRef]

40. Sperotto, F.; Friedman, K.G.; Son, M.B.F.; VanderPluym, C.J.; Newburger, J.W.; Dionne, A. Cardiac manifestations in SARS-CoV-2associated multisystem inflammatory syndrome in children: A comprehensive review and proposed clinical approach. Eur. J. Nucl. Med. Mol. Imaging 2021, 180, 307-322. [CrossRef] [PubMed]

41. Tenforde, M.W.; Morris, S.B. Multisystem Inflammatory Syndrome in Adults. Chest 2021, 159, 471-472. [CrossRef] 